\title{
PERSEPSI KONSUMEN TERHADAP SATE DAGING KAMBING DI KECAMATAN SANGATA UTARA KABUPATEN KUTAI TIMUR
}

\author{
(Costumer Perception Of Goat Meat Sate At North Sangatta Of East Kutai)
}

\author{
Ida Indrawati Waang, Joni Ariansyah, Nursida \\ Sekolah Tinggi Pertanian (STIPER) Kutai Timur \\ Jl. Soekarno Hatta No. 1 Sangatta Utara Kab. Kutai Timur, Kalimantan Timur, Indonesia \\ Email: joni_hublu@yahoo.com ; nursida@stiperkutim.ac.id
}

Article Submitted : 23-01-2019

Article Accepted : 31-01-2019

\begin{abstract}
This study aims to determine consumer perceptions of goat sate in North Sangatta base on personal aspects, social aspects, religious and cultural aspects, psychology aspects and product aspects. This studu have been done on Maret until April, 2018 in several food stalls that sell goat sate in the north Sangata sub-district. The sampling technique used is incidental sampling with total respondents is 30 buyers. Data is analyzed descriptively with a scoring method using a Likert scale. This study result had show that personal apsects is cunsumers agree if they buy goat sate accordance with their practical lifestyle and favorite food with perception value is 7.13 . Perception value from social aspects is 10.43 which means that consumers agree if they buy goat sate because of recommendations by friend and family believes that the taste and quality of goat sate is good. Religious and cultural aspects, perception value is 7.60 means that consumers disagree if consume goat sate contrary to religion and relieve trust. Psychology aspects with value is 14.30 result that consumers agree if goat sate is bad smell, can increase blood pressure and body vitality, and cook it long time. Product aspects, consumers also agree that the price of goat sate is more expensive than other sate, sale location are hard to find, less promotion, tastyseasoning, tough, less attractive presentation, aesthetics of a place to sell poorly with perception value is 25.60 .
\end{abstract}

Key word : consumers perception, meat goat sate, east kutai

\section{PENDAHULUAN}

Usaha dan pengembangan peternakan saat ini menunjukan prospek yang sangat cerah dan mempunyai peranan yang sangat penting dalam pertumbuhan ekonomi masyarakat dari sektor pertanian. Sebagian besar masyarakat dunia mengakui bahwa produk-produk peternakan memegang peranan yang sangat penting di masa yang akan datang. Peluang bisnis pada usaha peternakan selalu berkelanjutan dan menjanjikan. Hal ini dikarenakan produk pangan asal ternak seperti daging, telur dan susu mempunyai nilai gizi yang berkualitas.
Kecamatan Sangatta Utara adalah salah satu kecamatan di Kabupaten Kutai Timur yang memiliki peluang usaha sub sektor peternakan cukup potensial. Usaha tersebut meliputi budidaya, pengolahan, dan pemasaran hasil ternak, baik ternak besar, ternak kecil dan ternak unggas. Hal ini dikarenakan jumlah penduduk di Kecamatan Sangatta Utara semakin meningkat dan geliat ekonomi semakin tumbuh.

Kambing merupakan salah satu ternak kecil yang memiliki peranan penting di masyarakat. Beberapa acara seperti aqiqah, syukuran, sunatan dan bahkan acara pernikahan, kambing dapat dijadikan sebagai 
menu utama karena harganya masih terjangkau, dagingnya enak dan gurih, mudah didapatkan, pengolahannya mudah dan banyak variasi masakan yang dapat dibuat. Meskipun demikian, tingkat konsumsi daging kambing di Sangatta Utara masih rendah dibandingkan dengan jenis ternak potong lainnya seperti sapi dan babi. Berdasarkan data Badan Pusat Statistik Kutai Timur (2017) jumlah ternak sapi potong yang dipotong pada tahun 2016 sebanyak 131.654,42, kambing sebanyak 32.062,50 ekor, dan babi sebanyak 186.851,50 ekor.

Olahan kuliner dengan menggunakan bahan baku daging kambing sudah mulai bervariasi mulai dari sate, gulai, tongseng, bakso dan nugget. Sebagai salah satu kecamatan dengan penduduk terbanyak, pelaku usaha kuliner di Sangata Utara mengambil peluang dengan mengolah makanan berbahan daging kambing. Penduduk di sangatta utara mayoritas pendatang dari berbagai daerah, budaya, suku, dan agama. Hal ini dikarenakan Kecamatan Sangatta Utara memiliki potensi lapangan pekerjaan yang cukup banyak termasuk usaha kuliner.

Sate merupakan salah satu makanan tradisional yang banyak disukai oleh masyarakat Indonesia. Sate umumnya dibuat dengan menggunakan bahan baku daging yang dipotong kecil-kecil kemudian ditusukkan, lalu dibakar di atas arang. Penyajiannnya dilengkapi dengan kecap dan lainnya dan dimakan dengan nasi atau lontong. Sate biasanya dijumpai di restoran rumah makan dan warung tenda di pinggir jalan.

Usaha kuliner sate yang ada di Kecamatan Sangatta Utara umumnya terdapat di pinggir jalan dengan menggunakan tenda dan gerobak. Terdapat 3 jenis sate yang dijual, yaitu sate daging sapi, sate ayam, dan sate kambing. Namun jumlah pedagang sate kambing lebih sedikit dibandingkan dengan sate yang lainnya. Hal ini dimungkinkan sebagian besar masyarakat tidak menyukai sate kambing dengan berbagai alasan, baik dari aspek pribadi, aspek sosial, aspek agama dan budaya, aspek psikologi, maupun aspek produk dari sate kambing. Berdasarkan latar belakang tersebut, maka perlu dilakukan penelitian tujuan mengetahui persepsi konsumen terhadap sate daging kambing di sangata di tinjau dari aspek pribadi, aspek sosial, aspek agama dan budaya, aspek psikologi, maupun aspek produk.

\section{METODE PENELITIAN}

Penelitian ini dilaksanakan pada bulan Maret sampai April tahun 2018 di warung makan yang menjual sate kambing di Kecamatan Sangatta Utara, Kabupaten Kutai Timur. Metode pengumpulan data menggunakan kuesioner, wawancara, observasi dan studi pustaka. Data yang digunakan dari penelitian ini adalah data kualitatif berdasarkan hasil kuesioner dari usaha sate kambing. Jenis data yang digunakan adalah data primer dan data sekunder. Data primer berasal dari hasil wawancara langsung dengan konsumen di warung tenda dan pemilik atau pekerja warung sate, sedangkan data sekunder berasal dari buku-buku laporan dan lain-lain yang berasal dari instansi terkait dengan penelitian ini. Teknik sampling yang digunakan dalam penelitian ini adalah Sampling Incidental yaitu teknik pengambilan sampel secara kebetulan, responden adalah siapa saja yang membeli sate pada saat peneliti melakukan pengambilan data yang dianggap cocok sebagai sumber data (Darmadi, 2014). Jumlah sampel yang digunakan dalam penelitian sebanyak 30 responden. Data yang diperoleh dianalisa dengan metode skoring menggunakan Skala Likert 5 butir yaitu Sangat Setuju (SS), Setuju (S), Ragu-Ragu (R), Tidak Setuju (TS) dan Sangat Tidak Setuju (STS). Berdasarkan daftar pertanyaan yang telah disusun dalam kuesioner, data skor yang diperoleh kemudian ditabulasikan, dimana skor responden dijumlahkan dan jumlah ini merupakan total skor, kemudian 
total skor inilah yang ditafsirkan sebagai posisi responden dalam Skala Likert sehingga mempermudah dalam mengelompokkan dan mempresentasekan sebuah data. Skor penilaian untuk mengukur persepsi konsumen dalam mengkonsumsi sate kambing terlampir dalam Tabel 1.

Tabel 1. Kategori Penilaian Berdasarkan Persepsi Konsumen

\begin{tabular}{rlcc}
\hline No. & \multicolumn{1}{c}{ Indikator } & Skor Minimum & Skor Maksimum \\
\hline 1 & Aspek Pribadi (2 Instrumen) & 2 & 10 \\
2 & Aspek Sosial (3 Instrumen) & 3 & 15 \\
& Aspek Agama dan Budaya (3 & 3 & 15 \\
3 & Instrumen) & 4 & 20 \\
4 & Aspek Psikologi (4 Instrumen) & 7 & 35 \\
5 & Aspek Produk (7 Instrumen) & 19 & 95 \\
\hline
\end{tabular}

Total penilaian persepsi masingmasing skala dengan jumlah responden yang memilih skor pada skala tersebut. Dalam menginterpretasikan nilai persepsi suatu unsur secara keseluruhan oleh responden dibutuhkan suatu rentang skala. Adapun rumus rentang (range) bobot tiap skala, menurut Martila dan James dalam Kusuma (2008), adalah :

Rentang bobot tiap skala $=\frac{\text { Xib-Xik }}{X}$ Dimana :

$\mathrm{Xib}=$ Skor terbesar yang mungkin diperoleh dengan asumsi bahwa semua responden memberikan jawaban sangat Xik $=\quad \begin{aligned} & \text { setuju terhadap setiap unsur } \\ & \text { Skor terkecil yang mungkin }\end{aligned}$ diperoleh dengan asumsi bahwa semua responden memberikan jawaban sangat tidak setuju terhadap setiap unsur i.

$\mathrm{X}=$ Banyaknya skala pengukuran

Berdasarkan rumus tersebut, maka interval kelas untuk setiap aspek adalah

1. Aspek pribadi $=\frac{10-2}{5}=1.6$

2. Aspek Sosial $=\frac{15-3}{5}=2.4$

3. Aspek Agama dan Budaya $=\frac{15-3}{5}=$ 2.4

4. Aspek Psikologi $=\frac{20-4}{5}=3.2$

5. Aspek Produk $=\frac{35-7}{5}=5.6$

HASIL DAN PEMBAHASAN

Persepsi Konsumen Terhadap Sate

Daging kambing Berdasarkan Aspek

Pribadi

Tabel 2. Persepsi Konsumen Terhadap Sate daging kambing dari Aspek Pribadi

\begin{tabular}{llcccc}
\hline No & Istrumen & $\begin{array}{c}\text { Jumlah } \\
\text { Nilai }\end{array}$ & $\begin{array}{c}\text { Rata- } \\
\text { Rata }\end{array}$ & $\begin{array}{c}\text { Nilai } \\
\text { Persepsi }\end{array}$ & Kategori \\
\hline 1. & $\begin{array}{l}\text { Saya membeli sate daging kambing karena } \\
\text { sesuai dengan gaya hidup saya yang praktis }\end{array}$ & 110 & 3.66 & 7.13 & Setuju \\
2. $\begin{array}{l}\text { Saya membeli sate daging kambing karena } \\
\text { merupakan makanan favorit saya }\end{array}$ & 104 & 3.47 & & \\
\hline
\end{tabular}

Berdasarkan Tabel 2, terlihat bahwa dari aspek pribadi jumlah instrumen yang diteliti sebanyak 2 dengan nilai rata-rata sebesar 7.13. Nilai tersebut menunjukkan 
bahwa konsumen setuju jika membeli sate daging kambing karena sesuai dengan gaya hidupnya yang praktis dan merupakan makanan favorit. Kepercayaan konsumen akan suatu produk akan mendorong dirinya untuk memutuskan dan memilih produk yang ingin dikonsumsi. Kotler dan Amstrong (2005) menjelaskan bahwa keputusan seorang pembeli dipengaruhi oleh ciri-ciri kepribadiannya, termasuk usia dan daur hidupnya, pekerjaannya, kondisi ekonomi, gaya hidup, kepribadian dan konsep diri.

\section{Persepsi Konsumen Terhadap Sate Daging Kambing Dari Aspek Sosial}

Persepsi konsumen berdasarkan aspek sosial merupakan penilaian konsumen terhadap sate kambing berdasarkan lingkungan sosial, seperti saran dan peran orang di sekitarnya.

Tabel 3. Persepsi Konsumen Terhadap Sate Daging Kambing Dari Aspek Sosial

\begin{tabular}{llcccc}
\hline No & \multicolumn{1}{c}{ Istrumen } & $\begin{array}{c}\text { Jumlah } \\
\text { Nilai }\end{array}$ & $\begin{array}{c}\text { Rata- } \\
\text { Rata }\end{array}$ & $\begin{array}{c}\text { Nilai } \\
\text { Persepsi }\end{array}$ & Kategori \\
\hline 1. & $\begin{array}{l}\text { Saya membeli sate daging kambing karena } \\
\text { rekomendasi teman }\end{array}$ & 107 & 3.56 & 10.43 & Setuju \\
2. $\quad \begin{array}{l}\text { Saya membeli sate daging kambing karena } \\
\text { sebagian besar keluarga saya mempercayai }\end{array}$ & 104 & 3.47 & & \\
$\begin{array}{l}\text { rasa dan kualitasnya yang baik } \\
\text { Saya membeli sate daging kambing karena } \\
\text { iklannya menarik }\end{array}$ & 102 & 3.40 & & \\
\hline
\end{tabular}

Berdasarkan Tabel 3, diketahui bahwa konsumen setuju jika mereka membeli sate daging kambing karena rekomendasi dari teman, karena keluarga yang percaya akan kualitas sate daging kambing dan karena memiliki rasa dan kualitas daging yang baik. Aspek sosial yang diteliti meliputi teman, dan keluarga yang berperan dalam keputusan pembelian konsumen. Semakin tinggi hubungan dengan teman, keluarga dan orang tua, maka semakin tinggi keputusan konsumen untuk melakukan pembelian (Ghoni, 2014). Kotler dan Amstrong (2008) menyatakan bahwa tingkah laku konsumen juga dipengaruhi oleh faktor-faktor sosial seperti kelompok referensi, keluarga, serta peran dan status sosial konsumen. Kelas sosial kadang-kadang berupa suatu sistem kasta dimana anggota dari kasta yang berbeda untuk peranan-peranan tertentu dapat mengubah keanggotaan kasta mereka, termasuk dalam pembelian suatu produk.

\section{Persepsi Konsumen Terhadap Sate Daging Kambing Dari Aspek Agama dan Budaya}

Tabel 4. Persepsi Konsumen Terhadap Sate Daging Kambing Dari Aspek Agama dan Budaya

\begin{tabular}{llllll}
\hline No & \multicolumn{1}{c}{ Instrumen } & $\begin{array}{c}\text { Jumlah } \\
\text { Nilai }\end{array}$ & $\begin{array}{c}\text { Rata- } \\
\text { Rata }\end{array}$ & $\begin{array}{c}\text { Nilai } \\
\text { Persepsi }\end{array}$ & Kategori \\
\hline 1. & $\begin{array}{l}\text { Semua agama memperbolehkan makan sate } \\
\text { daging kambing }\end{array}$ & 112 & 3.73 & 7.60 & $\begin{array}{l}\text { Tidak } \\
\text { Seuju }\end{array}$ \\
2. $\begin{array}{l}\text { Terdapat suku tertentu yang tidak menyukai } \\
\text { sate daging kambing karena bertentangan } \\
\text { dengan kepercayaan }\end{array}$ & 68 & 2.27 & & \\
$\begin{array}{l}\text { Makan sate daging kambing dapat } \\
\text { melunturkan kepercayaan }\end{array}$ & 48 & 1.60 & \\
3. & & & & \\
\hline
\end{tabular}


Berdasarkan Tabel 4, diketahui bahwa responden tidak setuju jika mengkonsumsi sate daging kambing bertentangan dengan agama serta dapat melunturkan kepercayan, karena tidak ada agama dan suku tertentu yang melarang umatnya untuk mengkonsumsi sate daging kambing. Menurut Kotler dan Amstrong (2005), keyakinan (belief) adalah gambaran pemikiran yang dianut konsumen tentang suatu hal. Melalui tindakan dan belajar konsumen mendapatkan keyakinan dan sikap, keduanya mempengaruhi perilaku pembelian konsumen. Keyakinan mungkin berdasarkan pengetahuan, pendapat, atau kepercayaan (faith). Budaya adalah suatu cara hidup yang berkembang dan dimiliki bersama oleh sebuah kelompok orang dan diwariskan dari generasi ke generasi. Budaya terbentuk dari banyak unsur yang rumit, termasuk sistem agama dan politik, adat istiadat, bahasa, perkakas, pakaian, bangunan, dan karya seni. Faktor kebudayaan memberikan pengaruh paling luas pada tingkah laku konsumen.

\section{Persepsi Konsumen Terhadap Sate Daging Kambing Dari Aspek Psikologi}

Berdasarkan Tabel 5 di bawah, diketahui bahwa konsumen setuju jika sate daging kambing baunya brangus atau tidak sedap, dapat meningkatkan tekanan darah, waktu pembuatannya lama, serta dapat meningkatkan vitalitas tubuh dengan nilai persepsi sebesar 14.30. Kotler dan Amstrong (2005) menyatakan pilihan seseorang membeli dipengaruhi oleh empat faktor psikologis utama, yaitu: motivasi, persepsi belajar, kepercayaan dan sikap. Motivasi seseorang memiliki beberapa kebutuhan pada suatu waktu, bisa biogenik, yaitu muncul dari ketegangan fisiologis, seperti lapar, dahaga, kenyamanan, kebutuhan psikogenik, yaitu muncul dari ketegangan psikologis, seperti kebutuhan untuk diakui, harga diri dan merasa terhina di lingkungan masyarakat. Semakin tinggi motivasi, persepsi, pengetahuan, keyakinan dan sikap seseorang terhadap suatu produk, maka semakin tinggi keputusan konsumen untuk melakukan pembelian.

Tabel 5. Persepsi Konsumen Terhadap Sate Daging Kambing Dari Aspek Psikologi

\begin{tabular}{|c|c|c|c|c|c|}
\hline No & Istrumen & $\begin{array}{l}\text { Jumlah } \\
\text { Nilai }\end{array}$ & $\begin{array}{l}\text { Rata- } \\
\text { Rata }\end{array}$ & $\begin{array}{l}\text { Nilai } \\
\text { Persepsi }\end{array}$ & Kategori \\
\hline 1. & $\begin{array}{l}\text { Banyak orang merasa tidak nyaman makan } \\
\text { sate daging kambing karena baunya yang } \\
\text { brangus }\end{array}$ & 103 & 3.43 & 14.30 & Setuju \\
\hline 2. & $\begin{array}{l}\text { Makan sate daging kambing untuk } \\
\text { meningkatkan tekanan darah saya }\end{array}$ & 103 & 3.43 & & \\
\hline 3. & $\begin{array}{l}\text { Saya kesal ketika membeli sate daging } \\
\text { kambing karena membutuhkan waktu yang } \\
\text { lama untuk menunggu }\end{array}$ & 111 & 3.70 & & \\
\hline 4. & $\begin{array}{l}\text { Saya makan sate daging kambing karena } \\
\text { dapat menambah vitalitas tubuh }\end{array}$ & 112 & 3.73 & & \\
\hline
\end{tabular}




\section{Persepsi Konsumen Terhadap Sate Daging Kambing Dari Aspek Produk}

Tabel 6. Persepsi Konsumen Terhadap Sate Daging Kambing Dari Aspek Produk

\begin{tabular}{llllll}
\hline No & \multicolumn{1}{c}{ Istrumen } & $\begin{array}{c}\text { Jumlah } \\
\text { Nilai }\end{array}$ & $\begin{array}{c}\text { Rata- } \\
\text { Rata }\end{array}$ & $\begin{array}{c}\text { Nilai } \\
\text { Persepsi }\end{array}$ & Kategori \\
\hline 1. & $\begin{array}{l}\text { Harga sate daging kambing lebih mahal } \\
\text { daripada sate lain }\end{array}$ & 115 & 3.83 & 25.60 & Setuju \\
2. $\quad \begin{array}{l}\text { Tempat/lokasi penjualan sate daging } \\
\text { kambing sulit di cari (tidak strategis) }\end{array}$ & 109 & 3.63 & & \\
3. $\quad \begin{array}{l}\text { Promosi penjualan sate daging kambing di } \\
\text { Sangata kurang/tidak ada }\end{array}$ & 107 & 3.57 & \\
4. $\quad \begin{array}{l}\text { Hal yang membuat sate daging kambing } \\
\text { enak adalah bumbunya }\end{array}$ & 114 & 3.80 & \\
5. $\begin{array}{l}\text { Kualitas sate daging kambing tidka baik } \\
\text { karena alot/tidak empuk }\end{array}$ & 108 & 3.60 & \\
6. Teknik penyajian sate daging kambing & 108 & 3.60 & \\
kurang menarik & $\begin{array}{l}\text { Estetika tempat menjual sate daging kambing } \\
\text { kurang baik }\end{array}$ & 107 & 3.57 & \\
\hline
\end{tabular}

Berdasarkan Tabel 6, diketahui bahwa konsumen setuju jika sate daging kambing lebih mahal dari sate lain, lokasi penjualan susah dicari, promosi penjualan kurang, bumbu sate daging kambing enak, sate daging kambing tidak empuk (alot), teknik penyajian kurang menarik, dan estetika tempat menjual sate daging kambing kurang baik.

Harga sate daging kambing sangat berpengaruh terhadap daya beli konsumen, biasanya harga tidak menjadi masalah jika kualitas barang yang didapat sesuai dengan apa yang diharapkan oleh konsumen. Menurut Kotler dan Amstrong (2005), harga adalah apa yang harus diberikan oleh pembeli untuk mendapatkan suatu produk. Harga suatu produk dapat dipersepsikan murah atau mahal, sesuai dengan kualitas atau tidak sesuai dengan kualitas. Tjiptono (2015) menyatakan bila harga yang ditetapkan terlalu mahal, maka produk yang bersangkutan tidak akan terjangkau oleh pasar sasaran dan minat beli konsumen terhadap produk tersebut akan rendah. Harga yang dipilih akan berpengaruh langsung terhadap tingkat permintaan dan menentukan tingkat aktivitas pembelian serta harga juga akan mampu mendorong penjualan dan pangsa pasar.

Lokasi penjulan juga berperan dalam faktor produk karena semakin mudah lokasi penjulan ditemukan maka semakin mudah bagi konsumen untuk membelinya. Fannani (2006) menyatakan bahwa kemudahan memperoleh produk menempati urutan kedua setelah harga, karena semakin mudah suatu produk ditemukan maka semakin mudah konsumen untuk membelinya. Dalam hal ini lokasi penjulan harus berada di tempat yang strategis dan mudah dijangkau oleh konsumen. Menurut Tjiptono (2015) komponen lokasi meliputi: pemilihan lokasi yang strategis (mudah dijangkau), di daerah sekitar pusat perbelanjaan, dekat pemukiman penduduk, aman, dan nyaman bagi konsumen, adanya fasilitas yang mendukung seperti adanya lahan parkir, serta faktorfaktor yang lainnya.

Promosi sate daging kambing di Sangatta Utara masih belum banyak, konsumen biasanya membelinya karena sudah tahu lokasinya dan memang sudah menjadi langganan. Mereka bahkan hanya 
mengetahui beberapa lokasi penjulan sate daging kambing dari total penjual sate daging kambing yang ada di Sangatta Utara. Menurut Fannani (2006) dalam pengambilan keputusan, konsumen melewati fase pencarian informasi. Minimnya informasi mengenai suatu produk akan menyebabkan kegagalan tersendiri dalam pemasaran produk karena konsumen akhirnya tidak mampu mengenali produk yang ditawarkan tersebut. Disinilah promosi sebagai salah satu bagian dari pemberian informasi mengenai produk perlu dilakukan. Tjiptono (2015) juga menyataka bahwa kegiatan promosi mampu menarik perhatian konsumen agar tertarik untuk membeli produk, serta mampu memberi respon pembeli yang kuat, mendramatisasi penawaran produk dan mendongkrak penjualan dalam jangka pendek.

Kualitas produk merupakan hal yang sangat perlu diperhatikan oleh penjual, karena kualitas produk yang baik akan memberikan kepuasan konsumen. Kualitas produk bisa meliputi kualitas daging dan bumbu sate yang digunakan. Bumbu sate menjadi salah satu faktor pendukung yang meningkatkan rasa sate daging kambing. Rasa yang enak akan memberikan kepuasan kepada konsumen yang kemudian menjadi motivasi konsumen untuk membeli/menikmati produk tersebut. Rasa produk (sate daging kambing) sangat berpengaruh terhadap tingkat penjualan, semakin baik rasa yang didapatkan oleh konsumen maka mereka tidak akan mempermasalahkan harga yang harus mereka keluarkan untuk mendapatkannya. Pratiwi (2010) menyatakan bahwa kualitas produk mempunyai pengaruh terhadap keputusan pembelian. Jika kualitas produk semakin tinggi akan mempengaruhi tingginya keputusan pembelian. Hal yang sama juga dikemukakan oleh Kotler dan Amstrong (2005) yaitu apabila konsumen merasa puas dengan kinerja produk yang telah dibelinya maka akan menunjukkan kemungkinan lebih tinggi konsumen akan membeli kembali produk atau jasa tersebut.

Teknik penyajian dan estetika tempat penjualan juga berpengaruh terhadap keputusan konsumen. Teknik penyajian yang menarik akan menambah selera konsumen. Estetika penjulan juga perlu untuk diperhatikan semakin rapi dan bersih suatu tempat penjualan maka konsumen juga akan semakin merasa nyaman untuk mengunjunginya. Menurut Kotler dan Amstrong (2008) keadaan tempat penjualan (store atmosphere) tidak hanya dapat memberikan suasana lingkungan berbelanja yang menyenangkan saja tetapi juga dapat memberikan nilai tambah terhadap produk yang dijual. Pemandangan, suara, aroma dan pencahayaan gerai berkontribusi besar terhadap citra yang diproyeksikan kepada konsumen. Suasana gerai sebagai salah satu sarana komunikasi yang dapat berakibat positif dan menguntungkan bagi perusahaan.

\section{KESIMPULAN DAN SARAN}

\section{Kesimpulan}

Kesimpulan yang dapat diambil dari penelitian ini adalah sebagai berikut:

1. Konsumen setuju jika membeli sate daging kambing karena sesuai dengan gaya hidupnya yang praktis dan merupakan makanan favorit dengan nilai persepsi sebesar 7.13

2. Konsumen setuju jika mereka membeli sate daging kambing karena rekomendasi dari teman, karena keluarga yang yang percaya akan kualitas sate daging kambing dan karena memiliki rasa dan kualitas daging yang baik dengan nilai persepsi sebesar 10.43

3. Konsumen tidak setuju jika mengkonsumsi sate daging kambing bertentangan dengan agama serta dapat melunturkan kepercayaan, karena tidak ada agama dan suku tertentu yang melarang umatnya untuk mengkonsumsi sate daging 
kambing dengan nilai persepsi sebesar 7.60

4. Konsumen setuju jika sate daging kambing baunya brangus, dapat meningkatkan tekanan darah, waktu pembuatannya lama, serta dapat meningkatkan vitalitas tubuh dengan nilai perspsi sebesar 14.30

5. Konsumen setuju jika sate daging kambing lebih mahal dari sate lain, lokasi penjualan susah dicari, promosi penjualan kurang, bumbu sate daging kambing enak, sate daging kambing tidak empuk (alot), teknik penyajian kurang menarik, dan estetika tempat menjual sate daging kambing kurang baik dengan nilai persepsi sebesar 25.60

\section{Saran}

Penjual sate daging kambing diharapkan agar terus meningkatkan faktor produk sate daging kambing yang dijualnya baik dari segi rasa, kualitas, promosi, lokasi, penyajian dan estetika penjualan sehingga penjualannya dapat meningkat.

\section{DAFTAR PUSTAKA}

Badan Pusat Statistik. 2017. Kutai Timur Dalam Angka. Sangatta

Darmadi, H., 2014. Metode Penelitian Pendidikan dan Sosial. Alfabeta, Bandung

Fannani, Z. 2006. Analisis Faktor-Faktor Penentu Persistensi Laba. Jurnal Akuntansi dan Keuangan Indonesia. Vol. 7. No. 1. Jakarta.
Ghoni, A. 2014. Pengaruh Faktor Budaya, Sosial, Pribadi dann Psikologi terhadap Perilaku Konsumen (Studi Pada Pembelian Rumah di Griya Utama Banjordolu Semarang. Jurnal Ilmu \& Riset Manajemen. Vol. 3. No. 3. Semarang.

Kotler, P dan G. Amstrong. 2005. Manajemen Pemasaran. Edisi Ketiga Belas. Jilid Dua. Erlangga. Jakarta.

Kotler, P dan G. Amstrong. 2008. PrinsipPrinsip Pemasaran. Erlangga. Jakarta.

Kusuma, M. 2008. Analisis Tingkat Kepuasan Peternak Plasma Terhadap Pola Kemitraan Tunas Mekar di Kecamatan Nanggung, Bogor. (Skripsi). Program Studi Sosial Ekonomi Peternakan. Institut Pertanian Bogor, Bogor.

Pratiwi, P. A. O. A. 2010. Pengaruh Marketing Mix terhadap Keputusan Konsumen dalam Pembelian Mobil Avanza pada PT. Agung Automall Denpasar. Skripsi. Fakultas Ekonomi. Universitas Udayana. Bali.

Tjiptono, Fandy. 2015. Strategi Pemasaran. Penerbit Andi. Yogyakarta. 